\title{
Improving Preschool Students’ Engagement in Parent-Assisted Offline Play-based Activities
}

\author{
Dannah Mari Jelena N. Manongdo, Hannah Frances Marie R. Duya, Princess Caminia L. Moscoso, Johanna Angeline R. Palad, \\ Maria Sarra P. Villaruz, and Lizamarie C. Olegario \\ College of Education, University of the Philippines, Diliman, Quezon City, Philippines
}

\author{
How to cite \\ Manongdo, D. M. J. N., Duya, H. F. M. R., Moscoso, P. C. L., Palad, J. A. R., Villaruz, M. S. P., \& Olegario, L. C. (2021). \\ Improving Preschool Students' Engagement in Parent-Assisted Offline Play-based Activities. Asia Pacific Journal on \\ Curriculum Studies, 4(1), 8-24. https://doi.org/10.53420/apjcs.2021.2
}

\begin{abstract}
Student engagement is an important contributor to academic success. In the learning arrangement in a pre-school in Quezon city, students attended the online class and answered workbooks and worksheets as offline learning activities. These paper-and-pen activities did not motivate the students as they delayed doing the task. The present study aimed at incorporating play-based activities to increase the pre-school students' engagement in their offline learning activities. The study was conducted among 20 preschool students with the help of the parents in implementing the play-based offline activities. Responses regarding students' engagement were documented using the student engagement tool that parents accomplished every after offline activity, reflections notes, and survey questionnaires. A focus group discussion was also organized at the end of the study. The findings in this study show that the use of offline play-based activities improved student engagement in three dimensions - cognitive, emotion, and behavior. Students who previously expressed disinterest towards offline activities demonstrated self-motivation, conceptual understanding, engagement in physical activities, and have nurtured positive relationships among the students, their parents, and their siblings throughout the study. Considering the parents' feedback, the researchers further modified the design of the instructional activities to address prior poor student engagement by incorporating music and movement, balancing play and work in the activities, and by sending the guides earlier for the convenience of the parents. It is recommended that future research delve into the difference in engagement among different class hours, given that more students in the late morning and early afternoon sessions showed poorer engagement in offline paper-and-pencil activities prior to the intervention being made. Future research can also focus on the influence of fathers on their child's engagement, implementation of play-based activities in public schools adopting the modular approach, and parent-teacher relationship in managing and handling students' mental wellness.
\end{abstract}

Keywords: student engagement, play-based, offline learning activities, parental-assisted learning

\section{Introduction}

Student engagement is one of the important aspects of teaching and learning that teachers across the world desire. For teachers, learning takes place when students are actively participating in their lessons and activities. That being said, educators have been constantly searching for and trying new ways to maintain children's interest and active class participation. The pandemic, however, has brought about a lot of changes and restrictions within the country. The educational sector has been greatly compromised which resulted in the closure of schools and shifting of students' learning from the four walls of the classroom, to the four walls of their home. With the sudden shift to online learning, scholars are rethinking whether it would be beneficial for young learners to be exposed to such a new mode of learning. Although it is doable, it may not give adequate or appropriate opportunities for children to learn, considering their need for more interactions and hands-on activities (Kim, 2020). Additionally, the lack of opportunities to play and socialize can cause children to be frustrated about not being able to move around and explore because they are being confined in cramped spaces for extended periods (Iqbal \& Tayyab, 2021). These changes in the mode of learning emerge to the unexpected transitions that children need to undergo. There is a need to find teaching approaches that would make the transition easy for the children.

This action research focused on addressing the decreased engagement of preschool children in the activities. Months prior to the implementation of the intervention of action research, the lead researcher received feedback from the parents regarding the attitude of the children towards offline activities. The students found the learning activities to be not engaging enough because of 
the monotonous nature of the workbooks and worksheets. Parents reported that their children did not want to do their offline activities and delayed doing their tasks for reasons such as they were tired or wanted to play already and do something else. That being said, some parents had to resort to threatening their children into doing the activity, chasing after their children to sit them down, while some parents did not bother trying anymore, leaving the offline activity unaccomplished. Some even expressed their concern about their own and their children's mental health. In this light, the action research aimed at incorporating more activities that are anchored on play as a way to increase children's engagement in offline activities, with the assistance of the parents.

It is during this time that the increasing recognition of play in supporting young children's development, wellbeing, and learning has become more significant. Online learning classes limited students' opportunities to play. Not much has been done on how it affects children's engagement in an online learning setup. This research looked into the incorporation of play in the online classes of young children in order to increase their engagement in the activities, as well as their interactions with adults. It was hoped that the feelings of stress and frustration would also be addressed.

\section{Statement of the problem}

For this study, the researchers sought to find out whether the introduction of play-based activities as compared to the usual paper and pen tasks, would strengthen children's engagement in offline activities. It aimed to answer the following questions:

1. What changes in student engagement occurred when offline play-based activities are used?

2. What changes in the design of play-based activities occurred in response to the reaction/s of the students and parents to the activities?

3. What were the feedback of parents on the offline play-based activities?

In addressing the present concern, the researchers adopted the playful structure principle, together with the learning play approach. The approach involves balancing between work and play in children's learning with support from more knowledgeable others. The research and results determine whether introducing play-based offline activities will increase preschool students' engagement. The impact of the study benefits teachers in designing the curriculum in such a way that play is incorporated in the activities and can be properly implemented at home by the parents.

\section{Review of Related Literature}

In this section, significant studies concerning student engagement, play-based learning, and parental involvement are presented. This review also emphasizes the three dimensions of student engagement namely emotional, behavioral, and cognitive. Strategies for teachers to increase the students' engagement are also noted.

\section{Student engagement}

Student engagement is an important predictor of academic success. Students who are actively engaged and show interest in class are most likely to achieve effective learning in school. Teachers, through their teaching strategies and well-designed activities, can develop in students intrinsic motivation and authentic engagement in class (Nayir, 2017).

Engagement is defined as the quality of involvement, enthusiasm towards learning, and the student's interest level during learning (Fisher et al., 2018). It is a phenomenon that facilitates learning and increases academic success, although it cannot be directly observed (Turner \& Patrick, 2004). Among the indications of student engagement are enthusiasm, focus, and voluntary involvement in activities and assignments. Schlechty (2002) describes an engaged student as someone who performs activities with enthusiasm and focuses on and continues to study the assignments despite being challenged. Additionally, Bohemia et. al., (1997) posited that students who do their assignments enthusiastically are more likely to involve themselves in the task willingly.

\section{Dimensions of student engagement}

As a construct, student engagement has three dimensions: emotional, behavioral, and cognitive (Fredricks, Blumenfeld, \& Paris, 2004; Sakellariou \& Efthymia, 2016). According to Nayir (2017), emotional engagement happens when students are experiencing feelings of belongingness, positive or negative emotions towards classmates and teachers, and are showing interest in learning. Students who are emotionally engaged develop better confidence in academic and social aspects in school. 
Behavioral engagement, on the other hand, refers to students who participate well in the activities, pay attention to the tasks, and involve themselves in school activities. Behaviorally engaged students are seen to have good school attendance, partake in different learning experiences, and follow the rules present in school.

Students who exhibit cognitive engagement can self-regulate, manifest deep thinking, exert effort, and are persistent even when faced with challenges. Consistent with the previous study, Williford et al., (2013) researched the relationship between preschool children's engagement and their self-regulation. Results show that children who develop self-regulation of emotion, behavior, and cognition are more likely to function better in social and academic domains. Furthermore, positive and supportive relationships have been associated with children's academic, socio-emotional, and self-regulation development.

These dimensions of student engagement are interrelated. Students' sense of belonging in school affects their level of participation as well as their academic achievements. This means that for teachers to help the students increase their engagement, they need to work on these areas.

\section{Strategies to increase student engagement}

Keeping students engaged can be an arduous task. The varying levels of student engagement are important indicators of the quality of the activities and lessons presented in class (Saritepeci \& Cakir, 2015). That being said, teachers are required to have a wide variety of strategies at hand to which they have to carefully decide on when and how to use them. For teachers, adopting a strategy to teaching would mean taking one's teaching style and the learning needs of the students into consideration. Having a wide repertoire of strategies equips teachers with different teaching styles that can be applied effectively in specific situations, attracting students' attention and interest, and finally engaging them in the learning process (Sakellariou \& Efthymia, 2016).

Utilizing instructional strategies that improve the quality of teaching is vital in providing young learners with an effective learning process. Worthington (2008) studied kindergarten teachers' use of six micro-strategies intending to foster student engagement. These micro-strategies are as follows: a) using gestures, b) use of visual representations, c) using questions, d) providing waiting time, e) creating context, and f) modeling language use through extension \& expansion. The results of the study show that increased student engagement is caused by the combination of the abovementioned strategies. Further research suggests investigating the effectiveness of these micro-strategies and how various combinations of these can influence student engagement.

In line with the use of different strategies in increasing preschool students' engagement, young learners need to be exposed to an environment that fosters engagement through interaction. Williford et al. (2013) acknowledge the need for children to be in an environment accompanied by stimulating classroom activities and tasks, as well as, positive relationships with teachers and peers. In a study that examines the correlation between student engagement and self-regulation, engagement was measured using observational tools. One of the tools used is the Individualized Classroom Assessment Scoring System which contains 10 dimensions that measure children's classroom engagement. The first three dimensions are primarily focused on the relationship between the child and the teacher, the next four on the child's relationship with peers, and the last three on the task. This goes to show that children's engagement in learning tasks and activities is as important as engaging in social exchanges (Williford et al., 2013).

That being said, the previously mentioned strategies can be used by teachers, with the help of the parents, in addressing the present concern regarding student engagement in offline activities. These strategies can certainly be considered when designing and introducing play-based learning activities in preschool.

\section{Play-based learning}

Concerning student engagement, the physical environment or the access to engaging activities for preschool students is an important consideration in the present learning situation. As the front liners in instruction, teachers may bear the brunt of increased stress due to the abrupt changes in the delivery, as well as the steep change toward the use of Information and Communication Technology (ICT) (MacIntyre, Gregersen, \& Mercer, 2020). For preschool teachers, conducting online classes can be a quite challenging task since it means providing a safe and healthy online environment that is engaging and appropriate for children's learning, while simultaneously using play as a way for them to work with new technologies and explore new ways to use the materials at hand (McGinn, 2017).

Playful experiences offer a unique context for supportive and rich learning experiences in early childhood (Zosh et al., 2017). The play addresses the important aspects of a child's development in ways such as improving critical thinking skills and engagement in 
activities and socialization with other children or adults (Hunter and Walsh, 2014; Semrud-Clikeman, 2007). However, play is seen in a different light due to the recent turn of events. Presently, early childhood education teachers are assertive of how playbased approaches are significant, not just in supporting children's learning and achievement of academic goals, but more importantly, their socio-emotional development and their transition and adjustment to a different and new way of learning (O’Keeffe \& McNally, 2021).

There have been debates regarding what constitutes play-based learning. Current research leans towards the use of play in a more educational and cultural setting, where encounters or interactions and communication with more knowledgeable others are necessary to support learning through play. In line with this, play-based learning in early childhood education is currently viewed, in a more sociocultural perspective, as requiring adult interaction to support children's access to content knowledge about their culturally situated home and community experiences (Edwards \& Cutter-Mackenzie, 2014). In-depth discussions and research concerning play-based learning have resulted in the discovery of learning play. Learning play, which is a more relatable and relevant concept of play, emphasizes the relationships between children, adults, content, and context to understand the pedagogical practices in early childhood. While the role of adult-child interactions is seen to have a great impact on the child's learning, the learning play principle does not disregard the importance of free play and nonliteral play for young children (Smith, 2007).

Playful structure, which was anchored on Wood's integrated curriculum and pedagogical framework, is a principle proposed by the Early Years Enriched Curriculum Evaluation Project (EYECEP) as an alternative approach to providing children with developmentally appropriate learning opportunities (Walsh et al., 2010). The playful structure is designed to break down the dichotomy between formal and informal learning and between work and play. It is an initiative to encourage educators to maintain a degree of playfulness into the child's learning experience, while simultaneously maintaining an adequate structure to ensure the effectiveness of learning that is taking place (Walsh et al., 2010). In line with this approach is the "en passant" concept of learning. Reischmann (1986) explains that en passant features the following characteristics of learning: a) short learning situations, b) situations where less than half of the person's total motivation is on learning, and c) contents that are not clear, wherein there is no need for the learner to know in advance what and how to use it. Similarly, Hille et al., (2013) emphasize that the goal of en passant is not for children to know what they want to learn, instead, it aims for simple yet achievable goals such as playing one's favorite game, experiencing something memorable, and interacting with others. Such are the goals that this study aims to incorporate in children's offline activities, apart from helping children learn concepts in a more meaningful way.

\section{Parental involvement}

Recent research about the effects of the worldwide phenomena on the education and learning of children focuses on how play can contribute to mitigating the detrimental effects of the pandemic on children's overall health (Iqbal \& Tayyab, 2021). Play and hands-on activities are important in a child's learning and development, but they are not easy to do online. While minimizing the limitations of not being able to meet face to face, teachers try maximizing the benefits of online teaching and learning by involving the parents (Kim, 2020). Parents' involvement in supporting children's play is highlighted as a primary factor in their educational successes (Baker et al., 2016). Not to mention, the engagement and participation of the parents are heightened since young children's online learning, as well as online access, requires adult supervision, their availability, and involvement (Youn et al., 2012). The crucial support from parents, however, is not only limited to helping the children to navigate technology but also to collaborating with the teachers and offering support by helping in preparing the materials and including more hands-on activities within the lessons (Kim, 2020). A recent study shows that a vast majority of teachers encouraged parents to play with their children during the lockdown, and to introduce creative and interactive play opportunities, preferably outdoors, to avoid potential feelings of anxiety, frustration, or hyperactivity (O’Keeffe \& McNally, 2021; Iqbal \& Tayyab, 2021).

The success of children's online learning depends on different factors. There is the quality of activities designed by teachers, the willingness of children to adapt to the new learning platform, and the support and involvement of parents. Considering the current mode of learning, adapting a playful structure in today's curriculum is necessary and beneficial. Following this approach would help provide a good balance in the learning of young learners, giving opportunities for teachers to be creative in maximizing the available resources, and in encouraging parents to be involved in their child's learning and development.

\section{Methodology}

The purpose of this study is to use a play-based approach in designing the offline activities of preschool children to increase engagement in class. The researchers designed the offline play-based activities which the parents have implemented at home. The data were collected through interviews with parents and students and assessment tools that measure the level of engagement of children in the tasks. 


\section{Participants and setting}

The action research was implemented in a private school currently adopting the online mode of learning and teaching. The participants were 20 preschool students aged 4-5 years old. The participants were the students of the lead researcher and attended the online class from Monday to Friday for an hour and 30 minutes, and were given offline learning activities to accomplish with the assistance of the parents twice to thrice a week.

The locale was a preschool in Quezon City. The activities for the intervention were based on the existing curriculum of the school and were carried out for four (4) weeks. The activities were implemented twice a week in the safety of the children's home. The parents, with the lead researcher's instructions, implemented the offline learning activities and were tasked to prepare the materials needed, take note of changes in the behavior of the children, and participate in the activity.

\section{Research instruments}

In the execution of this study, the researchers sought different means to assess the student's level of engagement before, during, and after the implementation of play-based activities by gathering information from both the parents and the students. The research instruments used in this study consists of a Survey Questionnaire on Students' Engagement in the Offline Activities, a Student Engagement Tool that the parents answered to assess the level of their child's engagement, a Focus Group Discussion with the parents, Reflection Notes for the parents' feedback, and a Questionnaire for Students which was conducted through video recordings.

\section{Survey questionnaire on students' engagement in the current offline activities}

Before conducting the intervention, the lead researcher encouraged the parents to answer a survey regarding their children's behavior towards the current offline learning activities. The survey questionnaire was distributed electronically via Google forms. The survey aimed to gather information regarding how the students felt about the worksheets and workbook activities. It included questions about the parents' view on the offline activities and their children's behavior towards the activities. The survey consisted of a total of six (6) questions, four of which are answerable by yes or no with further explanations, and two long answer questions.

\section{Student engagement tool}

In the duration of the intervention, parents were asked to answer an engagement assessment tool after the offline play-based learning activity. The tool consisted of the 12 statements that measure the three dimensions of student engagement: cognition, behavior, and emotions (Nayir, 2017). In answering the tool, the parents were asked to check the behaviors that they have observed in their child while doing the activity. There were follow-up questions included in the tool which needed to be answered after each activity. The engagement tools were also varied to avoid instrument fatigue.

\section{Focus group discussion guide}

The parents were invited to join a focus group discussion (FGD) during the fourth and last week of the intervention. During the FGD, the parents were asked to share a) their experiences in implementing the activity, b) their observations regarding their child's behavior towards the activities, c) their comments or feedback on the activities, d) the problems/challenges they encountered during implementation, and e) their observed changes in their child's engagement in the activities.

\section{Reflection notes guide}

Reflection notes served as the parents' overall feedback regarding the offline play-based activities. The lead researcher sent parents a message asking them 2-3 questions about the activity. In general, the parents were asked to share their reflections and thoughts about the activities, the challenges encountered, and points for improvement. The reflection notes were done via Viber for a more convenient and easier exchange between the parents and the lead researcher. 


\section{Questionnaire for students}

The interview with the students was gathered through video recordings. The teacher asked the parents to record a video of the students answering the questions "What was fun in the activity? What was not fun?" This was done to gauge students' engagement, as well as their behavior towards the activities.

\section{Plan of action}

Since the study took place in a span of four (4) weeks, the researchers included a detailed schedule for the action plan and the specific dates for the implementation of the play-based offline activities. The agenda for each date is further elaborated from the Parents' Orientation, the weekly sending and implementation of Offline Play-based Activity Guides and eliciting of Parents' feedback, up to the Focus Group Discussion with the Parents.

\begin{tabular}{|c|c|}
\hline DATE & AGENDA (Tasks Achieved) \\
\hline $\begin{array}{l}\text { April 14, } 2021 \\
\text { (Wed) }\end{array}$ & $\begin{array}{l}\text { - Send a letter to parents via Viber. } \\
\text { - Schedule a short meeting/orientation with the parents (April 15, 2021). }\end{array}$ \\
\hline $\begin{array}{l}\text { April 15, } 2021 \\
\text { (Thu) }\end{array}$ & $\begin{array}{l}\text { - Orientation for the parents. } \\
\text { - Send a link for the survey to parents via Viber. }\end{array}$ \\
\hline $\begin{array}{l}\text { April 18, } 2021 \\
\text { (Sun) }\end{array}$ & $\begin{array}{l}\text { - Finalize the two activities to be implemented for Week } 1 . \\
\text { - Prepare the tools for Week } 1 \text { activities. }\end{array}$ \\
\hline \multicolumn{2}{|r|}{ WEEK 1} \\
\hline $\begin{array}{l}\text { April 19, } 2021 \\
\text { (Mon) }\end{array}$ & $\begin{array}{l}\text { - Send parents the Offline Activity Guide } 1 \\
\text { - Meet with the group to discuss the survey and delegation of tasks. }\end{array}$ \\
\hline $\begin{array}{l}\text { April 20, } 2021 \\
\text { (Tue) }\end{array}$ & $\begin{array}{l}\text { - Implement Offline Activity } 1 \\
\text { - Send parents the Engagement Tool } 1 \\
\text { - Remind parents to take a video of the children. } \\
\text { - Follow-up questions: } \\
\text { 1. Was the activity fun? } \\
\text { 2. Which part was fun? } \\
\text { 3. Which part was not fun? }\end{array}$ \\
\hline $\begin{array}{l}\text { April 21, } 2021 \\
\text { (Wed) }\end{array}$ & - Send parents the Offline Activity Guide 2 \\
\hline $\begin{array}{l}\text { April 22, } 2021 \\
\text { (Thu) }\end{array}$ & $\begin{array}{l}\text { - Implement Offline Activity } 2 \\
\text { - Send parents the Engagement Tool } 2 \\
\text { - Remind parents to take a video of the children. } \\
\text { - Follow-up questions: } \\
\text { 1. Did you like the activity? } \\
\text { 2. What part did you like the most? } \\
\text { 3. Was there anything in the activity you did not like? What is it? }\end{array}$ \\
\hline $\begin{array}{l}\text { April 23, } 2021 \\
\text { (Fri) }\end{array}$ & $\begin{array}{l}\text { - Ask for parents' Reflection Notes } 1 . \\
\text { - Follow-up questions: } \\
\text { 1. What do you think of the activities? } \\
\text { 2. What behavior/s (or changes in behavior) have you noticed in your child } \\
\text { while doing the offline play-based activities? } \\
\text { 3. What are your comments or feedback on the engagement tools you've } \\
\text { answered this week? }\end{array}$ \\
\hline
\end{tabular}




\begin{tabular}{|c|c|}
\hline $\begin{array}{l}\text { April 25, } 2021 \\
\text { (Sun) }\end{array}$ & $\begin{array}{l}\text { - Finalizing the two activities to be implemented for Week } 2 . \\
\text { - Preparing the tools for Week } 2 \text { activities. }\end{array}$ \\
\hline \multicolumn{2}{|r|}{ WEEK 2} \\
\hline $\begin{array}{l}\text { April 26, } 2021 \\
\text { (Mon) }\end{array}$ & $\begin{array}{l}\text { - Meeting with the group for updates on the implementation. } \\
\text { - Send parents the Offline Activity Guide } 3\end{array}$ \\
\hline $\begin{array}{l}\text { April 27, } 2021 \\
\text { (Tue) }\end{array}$ & $\begin{array}{l}\text { - Implement Offline Activity } 3 \\
\text { - Send parents the Engagement Tool } \mathbf{3} \\
\text { - Remind parents to take a video of the children } \\
\text { - Follow-up questions: } \\
\text { 1. What did we do in the activity? } \\
\text { 2. Did you have fun? } \\
\text { 3. What activity did you like? } \\
\text { 4. What did you learn from the activity? }\end{array}$ \\
\hline $\begin{array}{l}\text { April 28, } 2021 \\
\text { (Wed) }\end{array}$ & - Send parents the Offline Activity Guide 4 \\
\hline $\begin{array}{l}\text { April 29, } 2021 \\
\text { (Thu) }\end{array}$ & $\begin{array}{l}\text { - Implement Offline Activity } 4 \\
\text { - Send parents the Engagement Tool } 4 \\
\text { - } \quad \text { Remind parents to take a video of the children } \\
\text { 1. How did you feel about the activity? } \\
\text { 2. Why did you feel that way? } \\
\text { 3. Why do you think we did this activity? }\end{array}$ \\
\hline $\begin{array}{l}\text { April 30, } 2021 \\
\text { (Fri) }\end{array}$ & $\begin{array}{l}\text { - Ask for parents' Reflection Notes } 2 . \\
\text { Questions: } \\
\text { 1. Were the activities engaging? In what way? } \\
\text { 2. What are the behaviors you've observed in your child while doing the } \\
\text { activities? } \\
\text { 3. Are there things that must be changed or modified in the a) activities, b) } \\
\text { engagement tool? If yes, please list them down. }\end{array}$ \\
\hline $\begin{array}{l}\text { May 02, } 2021 \\
\text { (Sun) }\end{array}$ & $\begin{array}{l}\text { - Finalize the two activities to be implemented for Week } 3 . \\
\text { - Prepare the tools for Week } 3 \text { activities. }\end{array}$ \\
\hline \multicolumn{2}{|r|}{ WEEK 3} \\
\hline $\begin{array}{l}\text { May 03, } 2021 \\
\text { (Mon) }\end{array}$ & - Send parents the Offline Activity Guide 5 \\
\hline
\end{tabular}




\begin{tabular}{|c|c|}
\hline $\begin{array}{l}\text { May } 04,2021 \\
\text { (Tue) }\end{array}$ & $\begin{array}{l}\text { - Implement Offline Activity } 5 \\
\text { - Send parents the Engagement Tool } \mathbf{5} \\
\text { - } \text { Remind parents to take a video of the children. } \\
\text { - } \text { Follow-up questions: } \\
\text { 1. How did you find the activity? } \\
\text { 2. What was your favorite part of the activity? } \\
\text { 3. What did you learn from the activity? } \\
\text { - Meeting with the group. } \\
\text { Agenda: } \\
\text { - } \quad \text { Presentation of activities } \\
\text { - } \quad \text { Reporting on the engagement tool } \\
\text { Tasks: } \\
-\quad \text { Finalize engagement tools } \\
-\quad \text { Summary and analysis of data (engagement tool) } \\
-\quad \text { Familiarizing oneself with Focus Group Discussion. }\end{array}$ \\
\hline $\begin{array}{l}\text { May 05, } 2021 \\
\text { (Wed) }\end{array}$ & - Send parents the Offline Activity Guide 6 \\
\hline $\begin{array}{l}\text { May 06, } 2021 \\
\text { Thu) }\end{array}$ & $\begin{array}{l}\text { - Implement Offline Activity } 6 \\
\text { - Send parents the Engagement Tool } 6 \\
\text { - Remind parents to take a video of the children. } \\
\text { Follow-up questions: } \\
\text { 1. Do you think the activity was fun? } \\
\text { 2. What did you enjoy doing in the activity? } \\
\text { 3. What did you learn from the activity? } \\
\text { 4. Would you like to do more activities like worksheets? Or activities like } \\
\text { this? Why? }\end{array}$ \\
\hline $\begin{array}{l}\text { May 14, } 2021 \\
\text { (Fri) }\end{array}$ & $\begin{array}{l}\text { - Prepare for Focus Group Discussion on Friday (May 21, 2021) } \\
\text { - } \text { Message parents about the schedule of Focus Group Discussion (2:30-3:00 PM) }\end{array}$ \\
\hline \multicolumn{2}{|r|}{ WEEK 4} \\
\hline $\begin{array}{l}\text { May 17, } 2021 \\
\text { (Mon) }\end{array}$ & - $\quad$ Send parents the Offline Activity Guide $7 \& 8$. \\
\hline $\begin{array}{l}\text { May 18, } 2021 \\
\text { (Tue) }\end{array}$ & $\begin{array}{l}\text { - } \quad \text { Implement Offline Activity } 7 \\
\text { - } \quad \text { Send parents the Engagement Tool } 7\end{array}$ \\
\hline $\begin{array}{l}\text { May 20, } 2021 \\
\text { (Thu) }\end{array}$ & $\begin{array}{l}\text { - } \quad \text { Implement Offline Activity } 8 \\
\text { - Send parents the Engagement Tool } 8\end{array}$ \\
\hline $\begin{array}{l}\text { May } 21,2021 \\
\text { (Fri) }\end{array}$ & - Focus Group Discussion with the parents \\
\hline
\end{tabular}

\section{Data gathering procedure}

The previous offline activities of the participants, in the form of simple workbooks and worksheets were given two to three times a week. The children were to answer them at their own time and at their own pace, and were tasked to send them back to the teacher right after answering for feedback. As an intervention, the researchers modified the children's previous offline activities by injecting play-based approach to designing the offline learning activities. 
Before the implementation of the said activities, the teacher held an orientation for the parents to inform them of what the research was all about, what would happen during the implementation, the responsibilities of the participants, and the rationale behind the research. Afterward, the parents were asked to participate in a survey about their children's behavior towards the previous offline activities (i.e. workbook and worksheets). The survey was distributed electronically via Google forms. The results from the survey served as a confirmation of the issues and concerns raised by the lead researcher in the study. In designing the activities, the researchers used the existing curriculum of the school as a basis. The topics discussed during the intervention period were food, environment, and solar system.

Afterward, the lead researcher assigned to the parents the play-based activities that would be implemented at home. The parents were asked to implement two (2) activities per week for April and May. The lead researcher sent out the engagement tool for parents to answer after implementing the activity. The tool requires the parents to check the behaviors that they have observed in the child during the activity. Follow-up questions were included and modified to be relevant to the specific activity.

As part of the data collection, parents were asked to share their reflection notes every other week. The reflection notes were sent through Viber and contained the general assessment of the parents on the implemented activities. Apart from that, the parents were also tasked to take a video of the child answering questions regarding the activity that serves as the children's input in the data collection.

As additional data, parents were required to fill out a student engagement tool every after activity. There were a total of eight (8) engagement tools per participant for the whole intervention period. The participants were also asked to engage in a focus group discussion (FGD) wherein a group of parents shared their thoughts and experiences, as well as, the challenges encountered during the implementation of the activities.

\section{Data analysis}

The implementation of offline play-based activities sought to provide answers to the problems stated in this research. In analyzing the data, a thematic approach was used in identifying and organizing the relevant themes in the study. The researchers familiarized themselves with the present data by exploring the participants' responses for meanings to be associated with the concepts presented in this research. As part of the thematic analysis, a deductive approach was used in identifying and labeling relevant concepts and statements by viewing students' engagement as a construct consisting of the interrelations among behavior, cognition, and emotion. On the other hand, data were recorded using an inductive approach to determine and discover how students and parents perceive engagement through the changes that occurred in the students' behavior towards the offline activities. The responses that parents provided in the survey, engagement tools, reflection notes, as well as their answers to the questions during the focus group discussion, are consistent. Thus confirming that the positive changes in the students' behavior, cognition, and emotions occurred during and after the implementation of the offline play-based activities.

\section{Results and Discussion}

In this section, the study illustrates the changes in student engagement and changes in play-based activities resulting from the implementation of offline play-based activities. The researchers expound on the various themes that were revealed through analyzing the data gathered.

The research questions guiding this study were: 1) What changes in student engagement occurred when offline play-based activities are used? 2) What changes in the design of play-based activities occurred in response to the reaction/s of the students and parents to the activities? and 3) What were the feedback of parents on the offline play-based activities?

Data were gathered before the implementation through the survey questionnaire. Parents were asked about the engagement of their children with the workbook and worksheet activities. The responses showed that most children did their offline learning activities right away, but the reasons were extrinsic such as because of rewards, obedience, and fulfillment of the requirement.

Most children did their previous offline learning activities to be rewarded by their parents with things they preferred to do more such as playing, eating, sleeping, and watching TV. Some children only did their offline workbook/worksheet activities because they were told to do so, while some did their offline activities because they want to fulfill their requirement.

Qualitative data gathered during and after the intervention showed positive changes in the students' engagement in offline playbased activities had occurred . 


\section{Changes in student engagement}

The first research question was "What changes in student engagement occured when offline play-based activities were used?" In answering this question, the researchers explored the responses in the survey questionnaire and student engagement tools that reflected the changes in the students' engagement after the implementation of the play-based offline activities.

Parents who reported that their child did not do the offline activities right away and expressed disinterest towards them shared positive feedback regarding their child's engagement. The changes in the behavior of the students that occurred during the implementation demonstrated self-motivation, conceptual understanding, engagement in physical activities, and nurturing positive relationships.

\section{Self-motivation}

The definition of self-motivation in this research is the ability of the students to do the activities or tasks because they want to. It is initiating or taking charge of learning. Children who demonstrated self-motivation were observed to be showing enthusiasm and excitement as they initiated doing the activities, repeated the activities, and showed focus while doing the activity.

Initiative. Two of the offline play-based activities highlighted the children's initiative in responding. In the activity entitled My Plate, all parents stated that their child showed initiative in doing the activity. The students asked if they could help and then assisted in preparing and getting the materials for the activity and expressed their desire to start the activity immediately.

"Definitely, Karl was more into it. Last night he was asking if we could do offline activity without being prompted and in the middle of using the iPad." (P4)

The student, Karl (pseudonym) showed initiative by asking to do the activity without the need to be prompted. This was the same student who expressed negative feelings towards the former offline workbook activities by saying "awww!" every time he was being asked to answer the worksheets.

Repetition of activity. The students were observed to be repeating the play-based activities on their own.The children tended to repeat the tasks they found interesting and fun to do. Indeed, students who are motivated are likely to create more positive states, increasing the likelihood of repetition (Cheon et al., 2018).

"There were instances, even after the activity, I found Frances doing the same activity by herself." (P2)

Focus. Students' increased engagement was also observed in their ability to focus on the task at hand. Parents recounted that their children seemed to be more observant, attentive, and less distracted. Children were observed to be making observations and following and paying attention to the instructions. Children were less likely to be distracted when doing play-based offline activities compared to doing the workbooks and worksheets, where children were easily distracted because they wanted to play already. In doing the play-based offline activities, the only distraction mentioned by parents was that the students were excited about the activity materials.

\section{Conceptual understanding}

The students who showed increased engagement towards the offline play-based activities appeared to have a better understanding of the activity and were able to make sense of what they were doing. Students were able to recall past discussions and apply the concepts they learned to real-life situations rather than just memorizing. Their ability to make decisions and form their own opinions, as well as their ability to formulate questions, showed a better understanding of the concepts introduced.

Recognition and recall. One of the frequent observations of the parents is that students recall or remember the past lessons and discussions while the activities were being implemented. Aside from the offline play-based activities being fun, the children were reported to find them relatable since they involved all senses. Learning was deemed by the parents to happen naturally.

"So offline play-based activities are really good because they understand it more since it's very graphic and involves all the senses. Also, the children were able to absorb the concepts that they needed to learn more." (P9) 
Application of concepts. Apart from recalling past concepts, students were also able to apply things that were discussed during the implementation of play-based offline activities.

In the discussion on the cause and effect of saving water, the students learned to be cautious about their consumption of water and energy. How parents explained each scenario and used real-life situations as examples, also helped students make better choices and decisions. In a study conducted by Brown and Kane (1989), preschool students were most likely to apply concepts learned when encouraged to use prior taught and shown solutions.

"She applies the things she learned from the offline activities. She is being conscious of her usage of lights/water after discussion of sad earth and happy earth." (P6)

"Riley actually is enthusiastic when doing worksheets too, just like when she does play-based offline activities. But at her age, I think they absorb more when things are explained to them through play-based activities than in worksheets or through presentations." (P10)

Winthrop and McGivney (2016) regarded play as children's way of connecting concepts and skills and applying knowledge to different situations. Although learning happened when children answer their workbooks and worksheets, deeper learning transpired when they started doing the offline play-based activities. Students absorbed the concepts more and were able to make informed decisions on their own when placed in such a learning environment.

Curiosity. Another behavior that was observed was that the students became more curious. They asked more questions to make more sense of what they were learning. During the implementation, the students asked the most questions about the environment. In the activities entitled Happy Earth and Sad Earth and Water Filter, most of the questions of the children were very inquisitive and reflective. Questions asked were about the concepts being discussed. In the Leaf Rubbings activity, questions were more on the reason for doing the activity.

The students' questions varied and depended on their prior knowledge and experiences. Some questions sought information (i.e., What will happen?, What is a funnel?, Why are the leaves in different sizes?), while some were personal ones (i.e., Can we do it again? What color should I use?). There were also instances when their questions led to another question which was also mentioned by a parent in the FGD.

"He's very curious when it's offline play-based activities. Compared to the worksheets, (the offline based-activities are) not that super structured. (They're) free-flowing. For instance, he wanted to ask a question, and then it would lead to another question. So (we) covered a lot of topics..." (P9)

Among the changes that occurred in the students, their ability to ask meaningful questions was the most astonishing. These students were observed to be asking level one questions or questions that could easily be answered using facts. Prior to the intervention, most of the students did not ask questions during class discussions. Sometimes, the teacher would need to ask the students to know whether the students understood the discussion. However, with the play-based activities, more students asked questions and even asked level two questions, as well. The level two questions involved interpretation and analysis and usually started with the words 'how' or 'why'. Some of the factors that might have sparked curiosity were students' fondness of the topic, the topic being relatable, or the freshness of the activity or topic being introduced.

\section{Engagement in physical activities}

The implementation of play-based offline activities provided the students more opportunities to engage in physical activities such as playing and exploring their environment. The pandemic brought about little to no opportunities to play in today's online learning. The parents communicated this concern and they deemed that engagement in physical activities was a the critical shortcoming of online learning since, in a traditional setting, parents and children alike expect early childhood experiences to involve free play and outdoor activities (Dong, Cao, \& Li, 2020). As previously mentioned, one of the goals of this research was to provide children with opportunities to play. Some of the activities implemented included physical activities.

In an activity where the students were asked to gather leaves, both parents and students appreciated the part where they went outside to pick up leaves. The students were able to do the activity and at the same time, were amazed by the intricateness of nature, according to their parents. Students discovered that leaves could have different colors and textures. Some students even 
noticed the differences in the leaf patterns. In a different activity, the children seemed to enjoy the part where they danced to the video about the solar system.

The children were also observed to be very interested in doing the activities. Three activities namely Leaf Rubbings, Every Drop Counts, and Meet My Space Friends appeared to be the most interesting to the students as the activities included some form of music and movement. In their responses to the student engagement tool, the parents described their children to be jumping, singing, and smiling throughout the activity.

\section{Nurturing positive relationships}

Another observation on why the students were more engaged with the play-based activities than the workbooks and worksheets was because doing the play-based activities served as a bonding moment for the student, the parent, and for some, the siblings. In some video recordings of the students, some students mentioned they enjoyed the activity because they were doing it with their parents. Another parent shared that because the offline activities were play-based, the student's sibling got to join the activities and had fun as well. Consistent with the literature, although some advocate play to be child-centered, it remains an ideal venue for parents to engage fully in their child's development (Ginsburg, 2007). Not to mention, the pandemic seems to be the appropriate time for parents to fully support their children's learning as well as their mental health (O'Keeffe \& McNally, 2021; Iqbal \& Tayyab, 2021).

In answering the first research question, the researchers found that increased engagement in doing offline activities was certainly evident among the students upon implementation of the offline play-based activities. Students did not just do offline activities for a reward or just because they were told to, or because they felt it was a requirement. The students did the offline play-based activities because they wanted to, they were motivated, they understood the activity, they were curious about the topics related to the activities, they were interested, and they got to move around and interact with people.

In line with the self-determination theory, the previous observations from the parents affirm that student engagement is measured by the likelihood of students being motivated to do certain activities or tasks. Ryan and Deci (2000) proposed that if a student is self-motivated, he/she shows autonomy, competence, and relatedness. The students in this current research were able to demonstrate autonomy (initiating, repeating, and being enthusiastic about the activities), competence (doing the activities on their own, involving themselves in the activities and discussions), and relatedness (bonding with family members).

\section{Changes in the play-based activities}

The second research question asked was "What changes in the design of play-based activities occurred in response to the reaction/s of the students and parents to the activities?" In answering this question, the researchers explored the responses in the student engagement tools, FGD, and reflection notes that contained the suggestions for improvement regarding the play-based offline activities. The concerns were about time management, the inclusion of music and movement, and the balance between work and play.

\section{Time management}

Parents emphasized the need to consider the length of preparation for each activity and the accessibility of the materials needed. Initially, the offline play-based activity guides were sent a day before the date of implementation to refrain parents from implementing them earlier. This was done so as not to overwhelm students since there were also scheduled activities before the implementation dates.

"I think it's better for us parents to know the materials needed the weekend before the activities. I would also suggest if we can start the activity any time during the day and to receive the engagement tool beforehand.” (P10)

"Maybe with the materials needed. Sometimes you have to be very resourceful. In the activity about the group of foods, the foods should be available for him to appreciate and see the different kinds of go food, grow food." (P12)

Parents expressed the need to have the guide sent a bit earlier for better time management. The challenges mentioned by parents concerning time management involved scenarios where parents needed to attend to other children, or they were working, and/or did not have enough time to go out and buy. However, some parents addressed this concern by embracing their resourcefulness 
and creativity to provide their children a good experience of the activity. The activity guides were sent ahead of time upon the request of the parents.

\section{Music and movement}

Some parents suggested to include music and movement because their children were interested in it. In the Meet My Space Friends activity, children were able to sing and dance while learning about the solar system. When the children were asked what they enjoyed the most in the activity, some children answered dancing to the Planets song as their favorite part. Some even continued singing the song while doing the main activity.

\section{Work and play balance}

One parent expressed her concern about children finding other activities boring as a result of having offline activities that are playbased. She suggested that there should be a balance between work and play. Thus, the succeeding activities were designed in such a way that the students got to play, but at the same time do a more conventional activity. In the Every Drop Counts activity, the students played a water relay game and afterward did poster making about conserving water.

Based on the responses and suggestions of the parents regarding the offline play-based activities, the points for improvements were a) to allot enough time for parents to prepare the materials needed for the activity and at the same time lay some ground rules regarding the schedule of implementation, b) to include music and movement activities when needed, and c) to inject a bit of traditional pen-and-paper activities within the play-based activities.

\section{Parents' feedback}

The third research question asked, "What were the feedback of parents on the offline play-based activities?" Thought sharing during the FGD was examined to answer this question. Parents had numerous positive comments and feedback regarding the implementation of the offline play-based activities. The initial reactions and impressions of the parents regarding the implementation were expressions of happiness, relief, and excitement.

\section{Happiness}

Parents were happy because the offline activities were play-based and involved hands-on experiences which their children enjoyed. Knowing that their children were more engaged and happy with the activities gave them feelings of delight as well.

"We are happy, teacher. Because Mika likes hands-on activities. She is fond of doing things and not just doing activities from books. She likes activities where she touches things, where she creates things... So when we found out that there is such an offline activity, we're very happy. Cause we know that she will be more engaged in that. We observed that she also likes the book, but I think we find her more happy and excited with the offline activity." (P1)

\section{Relief}

Relief was also one of the emotions felt by the parents when they learned about the offline play-based activities. Parents found these kinds of offline activities to be convenient and easier to implement compared to the workbook and worksheets. Offline playbased activities were also seen as a good way to engage younger siblings as well.

“... so when you mentioned about that, it was okay with me. Cause I can deploy it anytime. And also, since it's play-based, his baby brother won't be disturbing him while doing the worksheets... But then, since it's play-based, the baby brother can join. Good for us since the brother can join and it will not be too hard for me to deploy it." (P12)

\section{Excitement}

Another positive comment made by a parent was excitement towards the play-based offline activities. She mentioned that the length of the online class was very limited, and most of the time her child wanted to do more activities. With the play-based offline activities, children got to enjoy the activity without being rushed. 
"I am happy and excited when I first heard about it. A 1-hour class doesn't seem enough for Lana because when there's an activity, sometimes it can't be helped that they have to rush in doing it. She really likes doing the activity now. If you noticed in the questions, she seems always excited when doing the offline activities." (P8)

\section{Mixed feelings}

A few parents expressed that they had mixed feelings upon learning about the implementation of the offline play-based activities. One parent shared that he expected that there would be challenges, especially in managing his schedule, considering that he was taking care of two kids.

"At first, actually it's mixed reaction... cause I'm taking care of two kids so I'm thinking how will I fit it in my schedule. As for Frances, I'm thinking it's a good opportunity that she will be doing hands-on activities... So there, when I heard about it, that's what came to mind. There are opportunities but also there are challenges. "(P2)

These initial reactions were consistent throughout the implementation. Parents expressed positive feedback and emotions towards the offline play-based activities based on their responses and reactions. Parents were enthusiastic about plans regarding the incorporation of the said activities in the students' online learning curriculum, but at the same time, anticipating some adjustments to be made on their end.

\section{Conclusion}

Therefore, the implementation of offline play-based activities improved the students' engagement as seen in their interest and enthusiasm during the intervention period compared to the time when they were simply asked to answer their workbooks. Fisher et al. (2018) defined student engagement as showing involvement, enthusiasm, and interest during learning. Nayir (2017) and Sakellariou and Efthymia (2016) highlighted that student engagement is measured cognitively, behaviorally, and emotionally. In the duration of the research, the children were able to exhibit the following behaviors: self-motivation (emotional engagement), conceptual understanding (cognitive engagement), engagement in physical activities (behavioral engagement), and nurturing positive relationships (emotional engagement).

The changes in the behavior of the students occurred due to the changes in the offline activity approach. From traditional pen-andpaper activities (i.e. workbooks and worksheets), the researchers utilized different instructional strategies to engage students while providing quality learning. Adapting the micro-strategies from Worthington's (2008) study, the offline play-based activities that were implemented involved the following strategies: using gestures and visual representations, asking questions, providing waiting time to practice patience, creating context, and providing opportunities to expand and extend one's language. As a follow-up on Worthington's suggestion to combine these micro-strategies to influence student engagement, this study was able to prove its effectiveness in increasing student engagement.

Apart from injecting play in the offline activities, the role of parents in assisting and implementing the activities has contributed much to the engagement of the students. Highlighting the concept of learning play, learning becomes more relatable and relevant because of the relationships between children and play, children and learning, and children and adults (Smith, 2007). Considering the current situation, involving parents or adults in children's play translates to quality time spent with each other. This helps boost children's socio-emotional development, and at the same time, children's engagement in learning activities (O'Keeffe \& McNally, 2021; Iqbal \& Tayyab, 2021).

Designing offline activities anchored on play during the pandemic can be challenging and demanding. Various considerations must be taken into account (i.e., accessibility to the materials, parents' schedule, and students' engagement) for it to be successful. However, it is doable. In exchange for bright ideas and out-of-the-box thinking, children still get to play. Children still get to have fun while learning, and parents get to contribute to their child's learning. Online learning should be seen in a better light both by parents and teachers and use this opportunity to build better communication and relationships to provide a better learning experience to the students.

\section{Recommendations}

The research showed that preschool students' engagement can be increased by parent-assisted offline play-based activities. The study focused on student engagement, but future studies can further explore the impact of the parent-assisted offline play-based activities on learning. While in this study, the parents appreciated the fact that their children had fun while learning, future studies 
can measure the depth of learning in parent- assisted offline play-based activities. The details about the parental involvement can also be explored further in order to find out what works and what does not work, as well as how time management can be maximized.

The researchers recommend additional research done on the relationship between students' engagement and the schedule of the class. The parents mentioned that apart from the design of the offline activities, the students' engagement was also influenced by the time or schedule of the class. Some parents expressed that since classes ended at around noon or in the afternoon, their children were less engaged and more likely to delay offline activities. Most children who belonged to the morning class did not have any issue with regards delaying the activities.

Another recommendation is to explore whether the parent's gender affects students' engagement. Most parents who implemented the activities were mothers, and only three fathers were involved in the implementation of the offline play-based activities.

Research about student engagement and paternal involvement in implementing offline play-based activities could be interesting. One can determine the differences in parental execution, as well as, the challenges experienced.

Since the study took place in a private school setting, it would be a good opportunity to introduce play-based activities in public school settings where the modular approach is widely used and identify the likelihood of adopting a more play-centered approach for preschool students. It would be interesting to discover how teachers could combat barriers such as lack of resources and funding in providing an approach that best fits the needs of a child, especially in this online distance learning environment.

Lastly, the researchers recommend additional research regarding a child's mental health in relation with the general online set-up. A striking feedback from one of the parents indicates that though the implementation of offline play-based activities was a big help in increasing student engagement in the new set-up, unpredictable situations and factors that affect the attitude of the student towards the activities still arise -- this includes losing enthusiasm in accomplishing any school activity, may it be play-based or not. Losing enthusiasm in doing any school activity is not surprising for any age, especially in this set-up, thus, additional research and information may assist as to how this can be combated. Furthermore, it would aid teachers and parents, altogether, in knowing how to react and respond to a child's needs if they become aware of a child's mental health and ability to adapt to an environment contrasting the ideal environment catered to the developmental areas of a child.

\section{References}

Baker, T. L., Wise, J., Kelley, G., \& Skiba, R. J. (2016). Identifying barriers: Creating solutions to improve family engagement. The School Community Journal, 26(2), 161-184.

Bomia L., Beluzo L., Demeester D., Elander K., Johnson M., \& Sheldon, B. (1997). The impact of teaching strategies on intrinsic motivation. Champaign, IL: ERIC Clearinghouse on Elementary and Early Childhood Education. (ED 418925 ).

Cheon, S. H., Reeve, J., Lee, Y., \& Lee, J. (2018). Why autonomy-supportive interventions work: Explaining the professional development of teachers' motivating style. Teaching and Teacher Education, 69, 43-51.

https://doi.org/10.1016/j.tate.2017.09.022

Christenson, S., Sinclair, M., Lehr, C., \& Godber, Y. (2001). Promoting Successful School Completion: Critical Conceptual and Methodological Guidelines. School Psychology Quarterly, 16, 468-484. https://doi.org/10.1521/scpq.16.4.468.19898.

Dong, C., Cao, S., \& Li, H. (2020). Young children's online learning during COVID-19 pandemic: Chinese parents' beliefs and attitudes. Children and Youth Services Review, 118, 105440. https://doi.org/10.1016/j.childyouth.2020.105440

Edwards, S. \& Cutter-Mackenzie, A. (2014). Next time we can be penguins: Expanding the Concept of Learning Play to Support Learning and Teaching About Sustainability in Early Childhood Education. In Play-Based Learning in Early Childhood Education (pp. 55-73). https://doi.org/10.1007/978-3-319-03740-0_2.

Fisher, R., Perényi, A., \& Birdthistle, N. (2018). The positive relationship between flipped and blended learning and student engagement, performance and satisfaction. Active Learning in Higher Education, 1-17.

Fredricks, A., Blumenfeld, P.C., \& Paris, A. H. (2004). School engagement: Potential of the concept, state of the evidence. Review of Educational Research, 74, 59-109. 
Ginsburg, K. (2007). The Importance of Play in Promoting Healthy Child Development and Maintaining Strong Parent-Child Bonds. Pediatrics, 119, 182-91. https://doi.org/10.1542/peds.2006-2697.

Hernik, J., \& Jaworska, E. (2018). The Effect Of Enjoyment On Learning. In Proceedings of INTED2018 Conference (pp. 508514). https://doi.org/10.21125/inted.2018.1087.

Hille, K., Evanschitzsky, P., \& Bauer, A. (2013). Das kind - die Entwicklung zwischen drei und sechs Jahreren. Köln: Bern.

Hunter, T., \& Glenda W. (2014). From Policy to Practice?: The Reality of Play in Primary School Classes in Northern Ireland. International Journal of Early Years Education 22(1), 19-36. https://doi.org/10.1080/09669760.2013.830561.

Iqbal, S.A. and Tayyab, N. (2021), COVID-19 and children: The mental and physical reverberations of the pandemic. Child Care Health Development, 47, 136-139. https://doi.org/10.1111/cch.12822

Kane, M. J., Brown, A. L., \& Long, C. (1989). Analogical transfer in young children: Analogies as tools for communication and exposition. Applied Cognitive Psychology, 3, 275-293.

MacIntyre, P. D., Gregersen, T., \& Mercer, S. (2020). Language teachers' coping strategies during the Covid-19 conversion to online teaching: Correlations with stress, wellbeing and negative emotions. System, 94, 102352.

https://doi.org/10.1016/j.system.2020.102352

McGinn, A. (2017). Play-based early childhood classrooms and the effect on pre-kindergarten social and academic achievement. Graduate Research Papers. 229. https://scholarworks.uni.edu/grp/229

Miks, J., \& McIlwaine, J. (2020, April 20). Keeping the world's children learning through covid-19. Retrieved March 17, 2021, from https://www.unicef.org/coronavirus/keeping-worlds-children-learning-through-covid-19

Nayir, F. (2017). The Relationship between Student Motivation and Class Engagement Levels. Eurasian Journal of Educational Research. 17, 59-78. https://doi.org/10.14689/ejer.2017.71.4.

O’Keeffe, C., \& McNally, S. (2021). 'Uncharted territory': Teachers' perspectives on play in early childhood classrooms in Ireland during the pandemic. European Early Childhood Education Research Journal, 29(1), 79-95. https://doi.org/10.1080/1350293x.2021.1872668

Reischmann, J. (1986). Learning “en passant": The Forgotten Dimension. The paper presented at the Conference of the American Association of Adult and Continuing Education, Hollywood, Florida, October 23, 1986. Retrieved from http://www.reischmannfam.de/lit/1986-AAACE-Hollywood.pdf

Ryan, R. M., \& Deci, E. L. (2000). Self-determination theory and the facilitation of intrinsic motivation, social development, and well-being. American Psychologist, 55, 68-78.

Sakellariou, M. \& Efthymia, T. (2016). Constructivist strategies that foster preschoolers' engagement. https://doi.org/10.13140/RG.2.2.16038.57925.

Sarıtepeci, M., \& Çakır, H. (2015). The Effect of Blended Learning Environments on Student Motivation and Student Engagement: A Study on Social Studies Course. Education \& Science/Egitim ve Bilim, 40(177). https://doi.org/10.15390/EB.2015.2592.

Schlechty P. C. (2002). Working on the work. San Francisco, CA: Jossey-Bass

Semrud-Clikeman, M. (2007) Social Competence in Children. In: Social Competence in Children. Springer, Boston, MA. https://doi.org/10.1007/978-0-387-71366-3_1 
Smith, A. (2007). Children's Rights and Early Childhood Education: Links to Theory and Advocacy. Australasian Journal of Early Childhood. 32, 1-8. 10.1177/183693910703200302.

Turner, J. C., \& Patrick, H. (2004). Motivational influences on student participation in classroom learning activities. Teachers College Record, 106(9), 1759-1795.

Walsh, G., Sproule, L., McGuinness, C., Trew, K., \& Ingram, G. (2010). Developmentally appropriate practice and play-based pedagogy in early years education: A literature review of research and practice. School of Psychology, Queen's University Belfast. Retrieved from

http://www.nicurriculum.org.uk/docs/foundation_stage/eye_curric_project/evaluation/Literature_Review.pdf

Williford, A. P., Vick Whittaker, J. E., Vitiello, V. E., \& Downer, J. T. (2013). Children's Engagement within the Preschool Classroom and Their Development of Self-Regulation. Early education and development, 24(2), $162-187$.

https://doi.org/10.1080/10409289.2011.628270

Winthrop, R., \& Mcgivney, E. (2016, May 19). Skills for a Changing World: Advancing Quality Learning for Vibrant Societies. Brookings. Retrieved from https:/www.brookings.edu/research/skills-for-a-changing-world/

Worthington, E. M. (2008). Effective learning environments in preschools, (UMI No. 1461916) [Master's thesis, Iowa State University]. ProQuest Dissertations Publishing.

Youn, M. H., Leon, J., \& Lee, K. J. (2012). The influence of maternal employment on children's learning growth and the role of parental involvement. Early Childhood Development and Care, 182(9), 1227-1246.

Zosh, J. M., Hopkins, E. J., Jensen, H., Liu, C., Neale, D., Hirsh-Pasek, K., Solis, S. L., \& Whitebread, D. (2017). Learning through play: a review of the evidence (white paper). The LEGO Foundation, DK. 